\title{
Comparing Trains Operated in Western Europe from Passenger Viewpoint
}

\author{
Jan Lizbetin ${ }^{1 *}$ \\ ${ }^{1}$ Department of Transport and Logistics, Faculty of Technology, Institute of Technology and Business in České Budějovice, České \\ Budějovice, 370 01, Czech Republic
}

\begin{abstract}
This paper provides a comparative analysis of trains used on high-speed railways in Western Europe. The analysis is based on a passenger satisfaction survey of transport service quality on said trains. The survey was carried out en route by interviews with passengers. The second part of the survey consisted in questionnaire where passengers expressed levels of satisfaction with different quality factors in rail transport and in their own opinion, they assessed the importance of the specific quality factors having an influence on user satisfaction with transport services. The survey was carried out in Germany, France, Belgium, Netherlands and Switzerland.
\end{abstract}

\section{Introduction}

The quality of transport service depends on a set of phenomena referred to as quality indicators. These indicators include regularity, reliability, safety, speed, reasonable transportation cost, environmental friendliness, transport comfort, or efficiency and availability. The current state of quality means the specific conditions where the individual aspects may be different and leading in a desired or undesired direction [1].

\section{Materials and Methods}

The survey of passenger satisfaction with transport service quality was carried out directly on selected routes. It was based on personal interview and questionnaire. [2] The survey was focused on high-speed railways in Germany, France, Belgium, Netherlands and Switzerland. Respondents were asked to fill in a questionnaire based on their experience with rail transport and based on their satisfaction with the actual (ongoing) transport service [3,4].

The questionnaire outputs are divided into a part with questions for passengers such as what is important for them and what is not and when are they satisfied with the provided quality of service and when they expect a higher level of quality [5]. The level of importance, or customer satisfaction scores were expressed on a 1-5 scale where 1 was the least important, or not satisfied at all, and 5 was the most important, or fully satisfied.

In conclusion of the analysis of a specific railway company, pros and cons of the service provided by specific carriers are illustrated [6-8].

\section{Results}

\subsection{Germany}

Modern train sets are used across the German network. They are very fast and reliable. As one of just a few, the railway network is not centralized in big cities, but rather connecting the North with the South and the East with the West. Rail line speed reaches the required maximum. The route from Hannover to Nuremberg is made by passengers on a ICE 2 train in three and half hours. This relation that is less than $500 \mathrm{~km}$ on road would be covered by a passenger car in a little less than 5 hours. The ICE train only stops at four stations on the route, namely Würzburg, Fulda, Kassel and Göttingen. In terms of commercial speed, this railway is a strong competitor to individual passenger transport [9-11].

Intervals between trains in one direction are $30-60$ minutes which is a sufficient frequency. Trains keep on the schedule. They leave at a fixed time and arrive on time at the destination.

DB dispatch trains with 6 to 12 cars. The train capacity varies from 360 to 690 seats. However, seat reservations are not is necessary for high-speed ICE trains so the train may be overcrowded and the passenger will not find a seat. It is a nuisance at rush hours which the German carrier is facing on busy routes [12].

The questionnaire results clearly show that highspeed rail transport is more expensive for passengers. Specifically, one-way and round-trip ticket prices without any tariff discount for the above relation Nuremberg - Hannover will be app. EUR 100 and EUR 180 respectively.

During travel, passengers are regularly informed about arrival times at next station directly by the train driver. There is no train personnel on the train. Thus it is

* Corresponding author: lizbetin@mail.vstecb.cz 
not possible to contact them en route in case of a question or complaint. Information boards are wellarranged and the DB application offers whatever the customer may expect, including delay announcements and the number of wagons, or the route. [13]

All parts of the train are modern and clean. Toilets are spacy and clean. The interiors are well lit using red and grey colours. Doors are controlled by electronic pushbuttons or by direct contact where the passenger comes up to the door and there is a pressure sensor built in the floor in place of a doormat that will open the door automatically.

ICE trains are designed for high-speed lines and protected by the necessary braking systems. Passengers' safety perception is very positive.

When the train is moving, noise and vibration are more distinct than those produced by other high-speed trains. ICE trains are higher and narrower than e.g. TGV trains, thus having a higher aerodynamic resistance. The front cars ICE 1 and 2 do not have a distinctive nose shape which increases noise and vibrations inside the car. Pressure oscillations are felt strongly by passengers when entering or exiting tunnels $[14,15]$.

Table 1. Summary of pros and cons resulting from the survey in Germany

\begin{tabular}{|c|c|}
\hline Pros & Cons \\
\hline Modern fleet & High occupancy of trains \\
\hline $\begin{array}{c}\text { Departure and arrival } \\
\text { accuracy }\end{array}$ & High price \\
\hline Seat reservations not required & Lack of information \\
\hline Dense transport network & $\begin{array}{c}\text { Noise and vibrations when } \\
\text { the train is moving }\end{array}$ \\
\hline High frequency of services
\end{tabular}

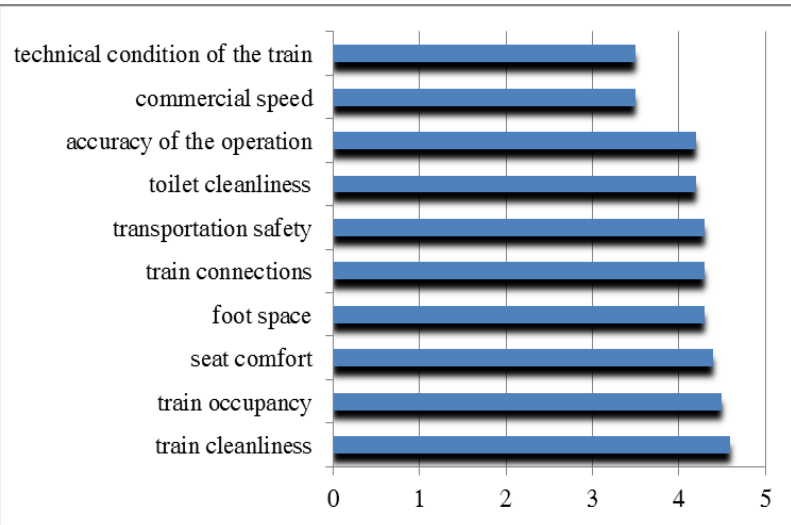

Fig. 1. Important and unimportant aspects for German passengers

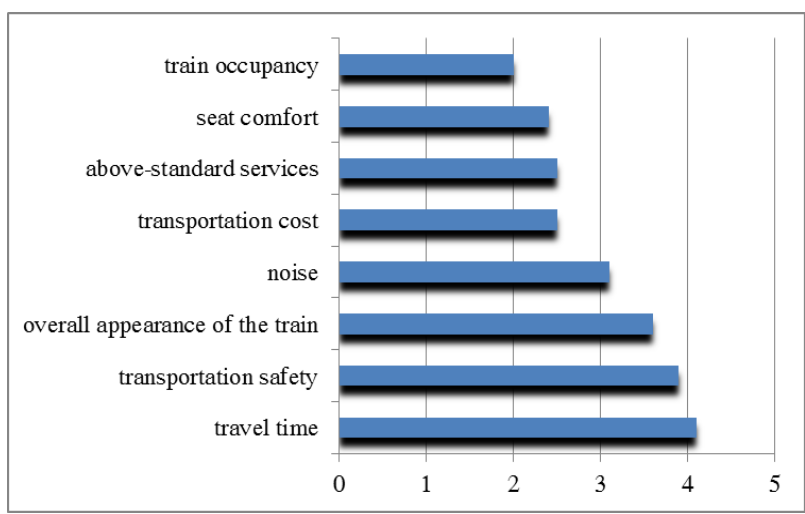

Fig. 2. German passengers' perception of service quality

\subsection{France}

As a result of co-operation between Belgium and France, the passengers can travel on a high-speed train of the French TGV already from Brussels where they board the train and in less than an hour and half, they reach the downtown of Paris, specifically the main train station Gare du Paris from where they can easily continue to travel as far as Barcelona [16].

The train capacity is always fully used. Seat reservations required from the passenger will not influence the selection of a specific seat. Seats are very wide, but with less space between the rows. The foot space is a little narrow. The on-board temperature is centrally controlled. No individual control by passengers is possible. Trains are equipped with the air-conditioning system. Trains are very long and consisting of two block train sets connected into one.

On the train route from Paris to Barcelona, several respondents noted they were not satisfied with smooth travel. Currently, the route to Barcelona is under construction in the territory of Spain and the running speed was much lower than $300 \mathrm{~km} /$ hour in this section. The rest of the route is all in operation with the maximum running speed of $300 \mathrm{~km} /$ hour and TGV trains will actually run at this speed for the whole journey [17, $18]$.

The passengers are used to quickly getting on and off the train. The time spent by the train at a station is extremely short and varies between $3-5$ minutes. It allows trains to be on time and keep on the schedule. Trains run hourly. The passengers are very satisfied with the density and reliability of rail service.

$\mathrm{TGV}$ trains always require seat reservations. The customer demand for transportation is huge because trains are fast. The train capacity is always fully used and the occupancy is $100 \%$. Nevertheless, the passengers were not satisfied with occupancy although every passenger has a booked seat. The current line capacity should be increased and extended because the rail transport demand is really high.

The respondents were highly satisfied with the accuracy of operation and information provided by the personnel. You can easily find your way around train stations and all information you need, can be found on 
information boards. The French personnel is very helpful and makes all efforts to arrange everything.

Transportation safety and commercial speed are considered by the passengers as a very important factor. The appearance or above-standard services are less important.

TGV trains are designed and constructed to run at high speeds with the minimum air resistance. Trains are lower set which lowers its centre of gravity and quite wider than e.g. ICE trains. Noise or vibrations are not transferred inside the car. TGV trains only reduce the speed to $230 \mathrm{~km} /$ hour when entering tunnels due to pressure decrease in the cabin. Pressure is markedly oscillating even in pressure-proof train cars.

Table 2. Summary of pros and cons resulting from the survey in France

\begin{tabular}{|c|c|}
\hline Pros & Cons \\
\hline High commercial speed & $\begin{array}{c}\text { Incomplete part of the } \\
\text { infrastructure impeding } \\
\text { the traffic }\end{array}$ \\
\hline Transportation safety & Train occupancy \\
\hline Operation accuracy & Transportation cost \\
\hline
\end{tabular}

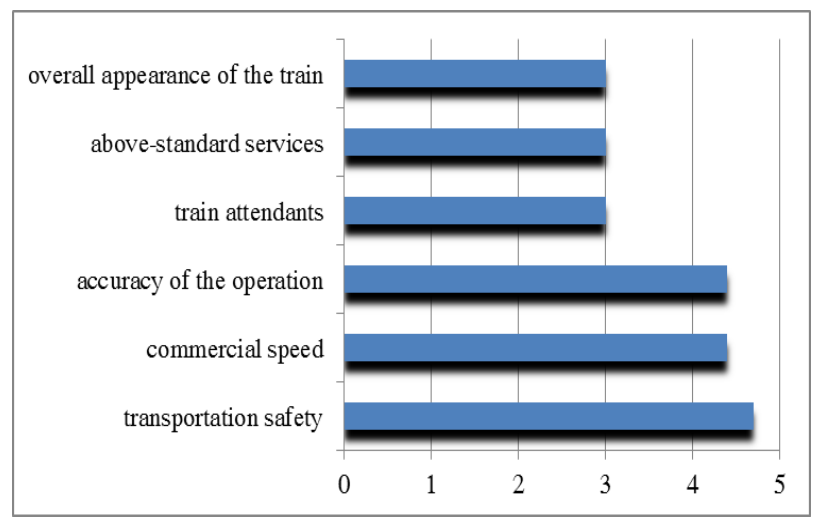

Fig. 3. Important and unimportant aspects for French passengers

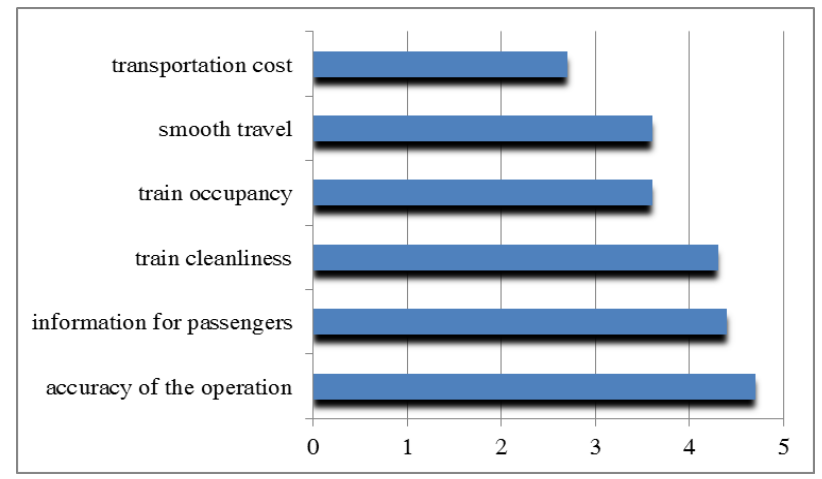

Fig. 4. French passengers' perception of service quality

\subsection{Netherlands - Belgium}

The countryside in the Netherlands and Belgium is very flat. The construction of corridors is not hindered by any hills or valleys. Railway tracks run directly without the need for tunnels or bridges. By virtue of the flat countryside, trains can reach higher speeds and construction costs are lower than those in hilly parts of Europe. Trains do not need to lower the speed when passing through curve track sections and ascending or descending on a track [16].

Leather seats in trains are very comfortable and provide reasonable foot space. The overall appearance of trains is good, the interiors as well as toilets are clean. In case of double-decker trains, all seats are arranged into groups of four around a side table to allow a good view. Every table is provided with an electric socket $220 \mathrm{~V}$ and Wi-Fi is free in the whole train.

Train intervals are short. In some sections, passenger trains run ten times per hour. You cannot find a line in the Netherlands with trains running in a less than halfhour interval. This fact was mentioned by one respondent in the interview. Train departure is sharp on time as well as arrival at the destination station.

The passengers were very satisfied with the train occupancy. Trains are extra long with many seats, comprising up to seven wagons. The occupancy is low and every passenger can find a comfortable seat.

The railway routes on the territory of the Netherlands and Belgium are much shorter than routes in other countries. As a result, the train fare is lower. The passengers were satisfied with transportation cost [19, 20].

All personnel can speak English fluently. It is very appreciated by foreign passengers because they can communicate with everyone at the station as well as on the train. Train attendants are well informed and always helpful. The announcement of the next station, arrival time at the next station and information about the alighting side platform is provided by the train driver both in English and French via the passenger information system. Information is continuously provided to passengers throughout the journey. There is no unnecessary delay at stations and the 3-5 minute interval for getting on and off the train is fully sufficient.

Trains are painted yellow and blue and those colours also appear in the interior. Trains are clean and in good technical condition. All cars provide a lowered curb for barrier-free access. Double-decker trains provide a panoramic view from the first deck. Passengers' safety perception is very positive. 
Table 3. Summary of pros and cons resulting from the survey in the Netherlands and Belgium

\begin{tabular}{|c|}
\hline Pros \\
\hline High train capacity \\
\hline High speed in the flat countryside \\
\hline All instructions also given in English \\
\hline Short interval between trains \\
\hline Seat reservations not required \\
\hline Electric power from windmills \\
\hline
\end{tabular}

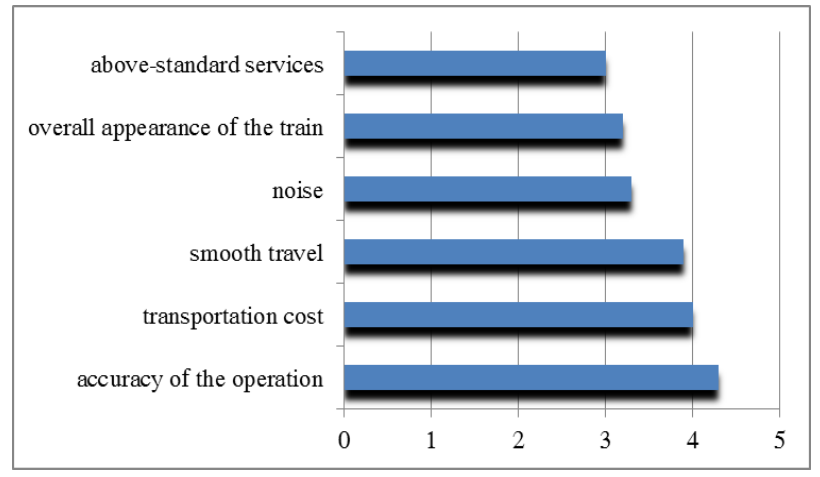

Fig. 5. Important aspects for passengers in the Netherlands and Belgium

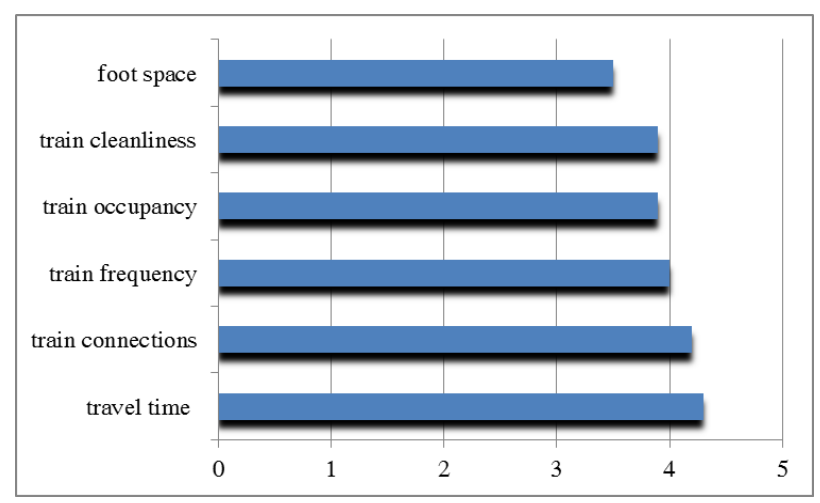

Fig. 6. Passengers' perception of service quality in the Netherlands and Belgium

\subsection{Switzerland}

Miscellaneous trains of the neighbouring carriers and the local SBB run on the Swiss railways. In general, trains are very comfortable. Rail transport is used by a high percentage of the population which indicates that users are satisfied with the rail travel comfort. The airconditioning is controlled at a reasonable temperature in respect to outdoor weather conditions [21].

Swiss rail is not the fastest, but far busiest with the shortest train intervals. Short running intervals are allowed by modern signalling installations. Trains reach speeds up to $200 \mathrm{~km} /$ hour. There is a high demand for the route from Zurich to Olten by reason of the travel time of 56 minutes. A one-hour travel is considered a kind of limit among passengers who are willing to commute to work on a daily basis. Swiss passengers were fully satisfied with the train frequency and connections. The interval is typically 15 to 30 minutes. [

Across Switzerland, the integrated transport system is used for urban transport and commuter transport as well as long-distance rail transport. Unlike Germany, the Swiss carrier is not struggling with a high occupancy since trains are dispatched in really short intervals with a sufficient capacity [22,23].

As previously mentioned, the integrated transport system in place on the whole territory makes it even more attractive for passengers, mainly in terms of transportation cost. Seat reservations are not required.

Unfortunately due to high diversity of trains dispatched to the neighbouring countries, train personnel is unable to keep up with the information flow as the passenger would expect. They are even unable to get information out to passengers concerning delays.

The passengers were thinking highly about safety and technical condition of trains. Trains are modern and each car provides barrier-free access.

Table 4. Summary of pros and cons resulting from the survey in Switzerland

\begin{tabular}{|c|c|}
\hline Pros & Cons \\
\hline $\begin{array}{c}\text { Integrated system by tariff } \\
\text { and operations }\end{array}$ & $\begin{array}{c}\text { Lack of information } \\
\text { provided by the personnel }\end{array}$ \\
\hline $\begin{array}{c}\text { Short intervals and travel } \\
\text { time }\end{array}$ & \\
\hline Seat reservations not required & \\
\hline
\end{tabular}

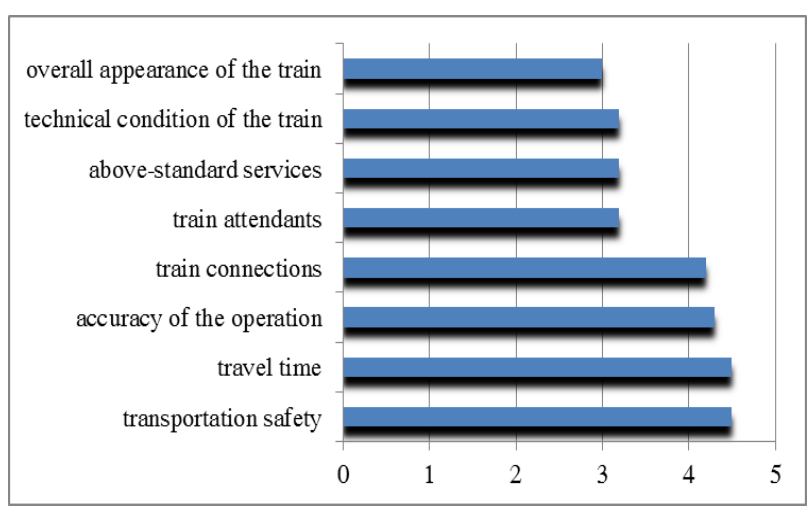

Fig. 7. Important and unimportant aspects for Swiss passengers 


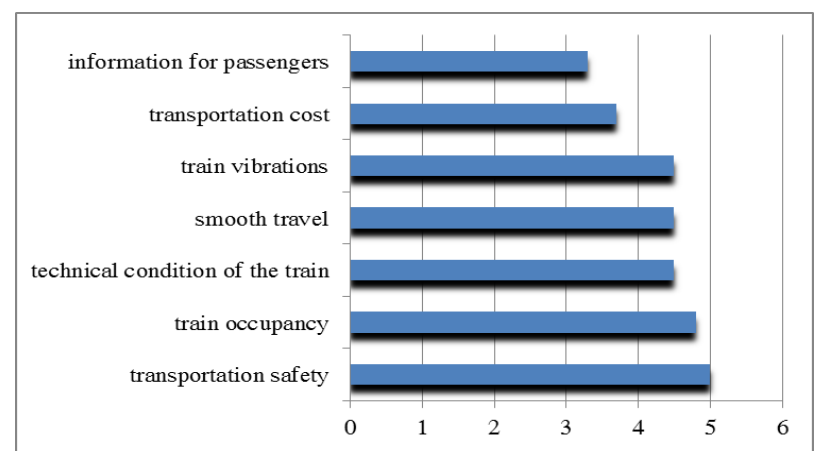

Fig. 8. Swiss passengers' perception of service quality

\section{Discussion}

The survey summarized in Fig. 1-8 indicates quite a difference in important aspects of the passenger rail transport across the European countries. Germany highly accentuates cleanliness of trains, the overall train occupancy and comfort. French passengers mainly look for transportation safety, travel speed and the accuracy of operation. Passengers in the Netherlands and Belgium consider the accuracy of operation, transportation cost and smooth travel as the most important. Swiss passengers highly insist on transportation safety, travel time and accuracy.

Figures 2, 4, 6 and 8 show that in principle, respondents were satisfied with all examined quality factors. There was no factor assessed as "unsatisfied". The results presented hereinunder show quite efficient operation of the passenger rail transport in given countries from the viewpoint of passengers.

\section{Conclusions}

The Czech Republic has the opportunity to use funding from the EU programmes to build a high-speed railway system as well as draw on the experience of other European countries from building good quality highspeed systems. Unfortunately, the financially favourable moment for building railway lines was missed. For building and ordering new trains, the preference must be oriented to the future and not based on the current requirements. The situation experienced during the construction of transit corridors that are currently insufficient in terms of their speed must be avoided.

Technical requirements, standards and the general technical development are the factors that have been ready for a long time. The consequent steps such as the adoption of legislation concerning the construction and the establishment of an executive authority, or the definition of financial and economic responsibility are the priorities that should immediately be tackled by the law makers. Until that time, the imaginary boundaries will be closed to the fast-paced modern times sought after by passengers to use rail transportation as often as passenger cars.

\section{References}

1. L. Nemecky. Aktuálni problémy v dopravě 2009, (2009)

2. R. Kampf, S. Lorincova, M. Hitka, O. Stopka, Sust., 9, 1561 (2017)

3. K. Lehutova, A. Krizanova, T. Kliestik, Transport Means - Proceedings of the International Conference, 258-261 (2013)

4. J. Sekulova, E. Nedeliakova, Logi, 6, 2, 79-89 (2015)

5. A. Nordborg, ACU. 84, 2, 289-300 (1998)

6. M. Halas, V. Zitricky, P. Blaho, Logi, 4, 1, 53-62 (2013)

7. V. Zitricky, L. Cerna, B. Abramovic, Procedia Engineering, 192, 994-999 (2017)

8. L. Cerna, V. Zitricky, J. Ponicky, 34th International Conference Mathematical Methods in Economics (MME), 126-131 (2016)

9. M. Vojtek, M. Kendra, V. Zitricky, J. Danis, MATEC Web of Conferences, 134, 00061 (2017)

10. G. Fedorko, P. Liptai, V. Molnar, EFA, 83, 30-46 (2018)

11. J.M. Duart, J.A. Pero-Sanz, J.I. Verdeja, RDM, 41, 1, 66-72 (2005)

12. H.L Zhao, Y.J. Li, 1st China/Japan/Korea Joint Symposium on Optimization of Structural and Mechanical Systems, 643-648 (1999)

13. R. Kampf, O. Stopka, I. Kubasakova, V. Zitricky. World Multidisciplinary Civil EngineeringArchitecture-Urban Planning Symposium. (2016) DOI: 10.1016/j.proeng.2016.08.623.

14. B. Bukova, E. Brumercikova, P. Kondek, P. Groma, Procedia Engineering, 187, 498-503 (2017)

15. S. Stoilova, T-TG, 25, 2, 587-595 (2018)

16. S. Yang, Y. Zeng, L.L. Cao, Y.H. Cheng, Y.C. Zhang, Advances in Education Research, 100, 101106 (2017)

17. G. Fedorko, V. Molnár, J. Strohmandl et al. Transport Means 2015 - Proceedings of the International Conference. 466-+ (2015)

18. J. Ponicky, J. Camaj, M. Kendra, AER-Advances in Engineering Research, 62, 191-194 (2016)

19. Y. G. Zhang, Q.Y. Liu, D.Y. Lei, X.P. Xu, J.Z. Zhao, ICEME 2016 and ABM 2016, 481-486 (2016)

20. E. Nedeliakova, J. Sekulova, I. Nedeliak, P. Majercak, Transport Means - Proceedings of the International Conference, 227-230 (2014)

21.Z. Tomes, Conference on Regulated and Unregulated Competition on Rails, 192-203 (2013)

22. W. Jiang, B.H. Mao, T. Chen, L.L. Yang, Y.Z. Yang, 6th Advanced Forum on Transportation of China (AFTC 2010), 90-93 (2010)

23. T. Skrucany, M. Kendra, M. Skorupa, J. Grencik, T. Figlus, Procedia Engineering, 192, 806-811 (2017) 